\title{
The Role of Educational Technology in the ESL Classroom
}

\author{
Md. Ruhul Amin* \\ Department of English, NPI University, Bangladesh \\ Submission: May 25, 2019; Published: November 06, 2019 \\ *Corresponding author: Md. Ruhul Amin, Department of English, NPI University, Bangladesh
}

\begin{abstract}
The use of technology has become an important part of the learning process in and out of the class. Technology continues to grow in importance as a tool to help teachers facilitate language learning for their learners. This study focuses on the role of using new technologies in learning English as a second/foreign language. It discussed different attitudes which support English language learners to increase their learning skills through using technologies. In this paper, the researcher defined the term technology and technology integration, explained the use of technology in language classroom, reviewed previous studies on using technologies in improving language learning skills, and stated certain recommendations for the better use of these technologies, which assist learners in improving their learning skills. The literature review indicated that the effective use of new technologies improves learners' language learning skills.
\end{abstract}

Keywords: Language Learning; Teaching; Digital; Technology; Internet

\section{Introduction}

\section{Background Information}

Staying acquainted with the latest technologies remains critical for the language teachers as the latter is usually dynamic and gets phased out easily with time. This, therefore, necessitates the need for the administrators in the education sector, the language trainers, and the students to work collaboratively and take advantage of the prevailing technologies before getting obsolete. Such an aspect, therefore, obligates the language trainers in specific and teachers in general to adopt a strategic approach on technology; such an approach view would encompass taking a wide array of considerations and principles regarding technology and language learning, language teaching and language use. The considerations should not only be made to the prevailing technological trends but also to the anticipated future technologies. The modern world has seen vast technological advancement in almost every facet of humanity. In the educational sector, technology has been critical in fostering learning by providing a platform for accessing information and delivering knowledge [1]. Essentially, most studies have been geared towards promoting Computer Assisted Language learning, with a majority emphasizing the need for development of professional bodies and organizations aimed at bolstering the application of technology in the education sector [2]. There are already bodies such as International Association for Language Learning Technology (IALLT) and
European Association for Computer Assisted Language Learning (EUROCALL). Additionally, various journals such as CALICO Journal, Journal of Computer-Mediated Communication, System, Computer Assisted Language Learning (CALL), ReCALL and Language Learning and Technology have been established to enhance the application of technology in language leaning in specific and communication in general [3]. Such developments have been critical for higher learning and have contributed to new language learning technology.

In most instances, however, the definition of technology is often confined to digital devices such as computers, Smartphone, and tablets. Such a definition limits the wide spectrum of mediational resources which are at the core of learning processes and specifically, the delivery of knowledge to the students. Put simply, teachers in all disciplines and particularly in languages instruction, increasingly rely on new technological processes, tools, and systems ranging from films to images, recordings, and written texts. This article begins by looking into how technological media has affected the forms and contexts of communication and expression with respect to language use and learning. In order to ensure a comprehensive understanding of the latter skills, three main strategies have been formulated that can greatly aid English learners and teachers, by integrating technology into practice. This paper will also serve to evaluate the suitability and applicability of any specific technology for different systems, grade levels and economic environments. 


\section{Research Question}

How can new technology be used to enhance language learning by second language and foreign language learners?

a) To critically analyze technological evolution in language learning.

b) To critically examine technological impact on the form and context of language use, learning, and teaching.

c) To recommend strategies that can be employed to enhance language learning by second langue and foreign language learners.

\section{Literature Review}

\section{Technology in Learning}

It has become apparent that students in the modern world must attain a certain level of technological skills in order to be able to fully benefit from different learning environments. Despite the advantages of technology that have been discussed by various scholars, researchers such as Bauerlein [4] and Carr take a negative view, looking at technology as a destructive force that has had negative effects on the literacy and cognitive processes of young people. Carl explains that the ethos associated with the twenty-first-century information access has led to some fragmented experience by the students, reduced ability to logically and critically think and a lessened focus on other people. This implies that despite the outlined advantages, there have been significant drawbacks, more so on the facet of the learners' social lives. Other scholars such as Thurlow [5] express their concern that technology today may be doing more harm than good to language learning and views digital environments that are not standardized as weakening, distorting and betraying the language learning process.

As such, teachers are often torn on between implementing and not implementing tech learning, and whether they are making the right decision when deciding on how to integrate technology into the classroom environment. However, a critical point to note is that teachers do not have an option to opt out and hence, they must find a way to integrate technology into the students' learning experience. Technology has become extremely pervasive and has greatly interwoven almost all human activities. As such, language teaching today, without the aid of the new technologies, may result in limited virtual or artificial learning experiences that do not fully addresses the needs of the learners and achieve the desired objectives. Essentially, teachers must, therefore, pay great attention to the use of technology, not because it is deemed to be a threat or boon, but rather, because technology bears a significant effect on the teaching and comprehension of language. Kern [6] explains that technology bears the ability to significantly affect how language is used by the people at various instances, not as a deterministic and autonomous force but rather, in the context of interaction with a wide array of factors that include but not limited to material constraints, situational context, social conventions, and individual volition.

From an analytical perspective, language teachers are often credited with the responsibility for enabling students to understand the connect between cultural norms and linguistics; it remains critically important for the teachers to focus on how language teaching has metamorphosed over the decades and passed in different materials and media. The main aim of this study is not critically reviewing the technology use in education and learning as elicited by Hubbard [7], Chapelle \& Blake $[8,9]$ but rather, to focus on the decision-making process and pertinent issues relative to technological use in the learning, use and teaching of languages that are not often addressed in studies with the hope of contributing to knowledge.

\section{Technological Impact on the Form and Context of Language Leaning}

Following the invention of writing many centuries ago, technology and language have remained significantlyintertwined. Firstly, not only did the invention of writing make language presentable and visible, it also enhanced the communication of people across the globe [6]. With time, written words and printing proved a most significant mode of communication, and a critical tool that has been widely embraced by almost all the societies across the globe. Additionally, writing has greatly contributed to the growth of language as a critical object of analysis. Such study of grammar has led to the emergence of various rules, parts of speech and metalinguistic notion of words that have explicitly been taught in addition to being standardized in grammars and dictionaries. Analytically, writing can be viewed as the technology of language. This is because the latter has greatly developed and metamorphosed over the decades, and it is now inseparable from language learning [6].

As such, the advent of the writing technology led to the development of great communicative power in language, by providing a critical way through which knowledge could be recorded and accumulated to enhance human possibilities of expression and bridge the communication divides among peoples around the world. Essentially, modern day communication relies on writing as the most fundamental input, as the latter is intrinsically intertwined with sign systems as well as technological systems. The advancement in technology has also led to the development in the way people communicate; new technological platforms have been developed that are more efficient and faster in information transmission and sharing, However, all the systems rely on human input for them to function. Learning to use such systems effectively has emerged to be a critical need that must be addressed in the linguistics discipline (Lai, 2015). For instance, the 21st century has seen the emergence and rapid development of social network communities that are made to make people "stay connected" 
to one another, by providing means of sharing status updates and information. However, such mediums have critically been successful because people have learned how to communicate through them. Likewise, technological advancements are always linked with people's ability to communicate, which, in turn, is based on the language use.

Analytically, how people read and write and the tools that they use to do so is very critical. Each tool used for the purpose of communication is associated with various limitations, affordances, feels and techniques of use, and material property; these aspects end up building a specific relationship between the readership (or the writers) and the textual information. This fact is depicted in a study by Kittler [10], who asserts simply that "... writing instruments contribute to our thoughts" (p.195). This implies that a change in the technological tools can change the communication possibilities as experienced in the modern world. Following the ever-changing technologies, there is the need for cultural know-how to adapt to such changes, and specifically gauge technological form irrespective of whether an individual is the sender of the message or the recipient. According to Kern [6] language technology significantly varies, and proficiency in one does not always depict proficiency in all. Literacy is the cultural know-how that enables an individual to navigate and get acquainted with the various language forms and contexts. Literacy bears the ability to preserve a wide array of conventions across different technologies. This is well articulated by Bolter and Grusin [11], Manogvich, Gitelm \& Pingeree [12,13], who argues that the remediation of the past media by the people greatly impacts the communication design and aids in the expression of the ideas and values of the particular communication. In such a case, the effect on the language users and learners is quite clear; there is the need to improve the knowledge of genres, pragmatics, vocabulary, and grammar, as well as the need for developing a predisposition and a critical eye regarding ideologies, meanings, contexts, forms and other culturally encoded linguistic elements in various material media.

\section{Ethics, Values, and Culture and the Internet}

With ever advancing technologies, a consideration of the impact of the internet with respect to ethics, values, and culture is critical, even more so in language use and learning. Essentially, the internet is a pool of information that is readily available to all the people, who have the internet connection. The twenty-first century has seen increased coverage in the internet connection; more people today living in both developing and developed countries today have internet access; thanks to the emergence of smart devices such as a smartphone, tablets and PCs that have internet capability. In addition, tools that allow the internet user to easily copy and edit information, and other materials have also increased. This has enhanced the notion propagated by Bakhtin (1986), that people's words are often filled with other people's texts and information; using other people's materials and information found on the internet has become the order of the day- people nowadays care less about giving credits or even acknowledging the borrowed pieces.

As such, the repurposing and remixing exhibited by the internet is to a greater extent authorless and an anonymous. According to Pecorari [14] and Chandrasoma, Thompson, and Pennycook [15], such a notion has greatly contributed to the prevailing trends on plagiarism and cultural relativism of the internet with respect to information sharing. Various debates have been advanced by numerous scholars specifically on the multimodal texts that are usually found on the internet and whether such material should be freely available on the internet. Specifically, Perkel [16] explains that the use of multimodal texts from the internet not only amounts to language borrowing but also the design, since the feel, sound and look of the digital material can be copy-pasted as easily as language or material texts. In this retrospect, Wertsch [17] explains that often, people often tend to look at copyrights and more so, original creations as emanating from nothing and associate such with genius. However, this is an aspect that people take to be real but only exists in the imaginations, as little focus is given to the cultural resources and the mediational means that the originator of the idea, concept of information relied on to come up with his or her proposition [17].

Such notions by the prior scholars indicate the need for interactive language classes that exhibits intense cultural dissection, analysis, and comparison in order to expose the learners to the wide array of sociocultural values that affect their language conception in specific and communication in general. Nevertheless, in the education discipline, the students exhibit significant understanding of the conventions and culture relevant to their professions as well as how they have developed over the decades. On a different note, it is critical to also understand the concept of personal presentation with respect to learning and communication. Individuals engaging in online communications usually tend to exhibit greater control on their personal appearance and presentation as compared to the face to face communication. This is especially true for the text-only communication, whereby one can greatly choose how to control expression and self-image. This in line with the hyper-personal concept that was coined by Walther [18], in which the researcher claims that individuals who use computermediated communication environments experience stronger affect or are able to express themselves fully as compared to their counterparts who rely on the face to face communication. Such a notion has greatly shaped how people communicate and articulate themselves and hence has significantly contributed to the growth of the language.

From an analytical perspective, textual communication can lead to underestimation or overestimate of some people by others. However, while this may not appear to be an issue, in communication environments where the identity of the other 
participants is undisclosed, or in anonymous communication over the internet, the language learners must always remain open minded in the interaction as such forms the basis of the student's impression regarding the specific sociocultural background of the other participants in the conversation. Again, the internet entails a wide array of text-based communication, and hence characterized by high-level anonymity. The relative distance and anonymity afforded by such mode of communication can easily fall into risks of verbal attack, interpersonal tensions, misunderstandings, and misconceptions. Studies by Ware [19] \& Hanna and deNooy [20] noted various verbal attacks that are usually associated with electronic modes of communication. Nevertheless, the authors note that the prevalence of the linguistic violence usually increases when there is unsupervised learning or exchange between the learners in a virtual environment, without a moderator or a teacher on the site. It is, therefore, critical for the learners to take anonymity as decisive factor in communication, which can positively or negatively impact one's personal presentation in online forums and in electronic communications in general. The learners need to develop an online linguistic culture that is based on a wise choice of words, one that fit the content and context of the exchange. Zhao [21] explains that critical student peer reviews often take place when there is anonymity (using computer mediated communication) as compared to reviews in a face to face setting. This is because the anonymity aspect seemingly does away with an individual's sense of social responsibility, and hence one tends to be more honest regarding their review and feedback, however blunt it may sound. From a different perspective, it is also critical to note any miscommunication that may result from communication in electronic media. A study by Ware [19] on online communication between American students of German and German students of English established that the computer-mediated communication nature of the students engagements encouraged brevity and speed in sustained discourse, and in the long run resulted in missed opportunities and disengagement, which in turn hinders cross-cultural learning. To understand these findings, it is critical to reflect on Kramsch \& Thorner [22], who explain that besides the linguistic misunderstanding or the technological medium that leads to flaws in cross-cultural computer-mediated communication, the stylistic standard of a specific genre, as well as cultural frames too, are critical aspects that must be considered as well.

In a study that examinee French Learners sponsored by the Le Monde Magazine to establish the essence of genres of communication, Hanna \& deNooy [20] revealed that discussions in general, was not something common across all the participants but rather varied on the medium and culture. The authors also observed that to the learners, following the discourse rules of the online communities and socialization winningest was ore regarded as compared to the linguistic accuracy and politeness by the students. As such, it is agreeable that culture and genre plays a critical role in shaping the constraints and conditions of the contexts of communication through language competence and extension. From these arguments, it can be inferred that online contact does not necessarily contribute to intercultural understanding and linguistic competence by the learners, in a setting that requires an individual to get acquainted with the various institutional cultures, interaction styles, and genres in a broader way.

\section{Research Methodology}

\section{Introduction}

This section presents a full description of the research design, procedure, and how the study was carried out. It encompasses the research philosophy and the research design that were adopted.

\section{Research Philosophy}

Eriksson and Kovalainen [23] explain that research philosophies are broadly classified into two main paradigms; interpretivism and positivism. The authors continue to define the interpretivist paradigm as being more subjective and assuming the existence of multiple realities of the phenomenon being investigated. Owing to this, this paradigm is well suited for qualitative studies, which are often exploratory and generally attempt to answer the why and how research questions. In the same way, McLachlan and Garcia [24] state that the positivist paradigm is more objective and hence better suited for quantitative studies, which often entail statistical analysis aimed at reaching a decision, to prove or disprove the research hypotheses, or to form confirm the truth of a critical argument in a given study. In consideration of this and because the study will entail a qualitative approach to tackle the research problem presented in the introduction section, an interpretivist research philosophy and qualitative method have been adopted.

\section{Case Study Design}

Creswell \& Clark [25] explain that any given study must follow a predefined framework of steps that are aimed at attaining the study objectives, by answering the research questions. In support of this, Patton [26] explains that the research design adopted must be systematic and in alignment with the purpose of the study. This study follows a case study design that entails a review of the literature regarding teaching language using technology to students learning a second or new foreign language. This research, therefore, is a critical analysis of how technology can be used to bolster language learning by drawing arguments from various studies regarding technology use in the linguistic discipline.

\section{Results}

\section{Development of the Specific Learning Goals}

First, any given learning process must be defined by a specific set of objectives that the teacher wishes to achieve. Essentially, learning that is not guided by any specific objective 
is bound to fail, as there is no sure way of determining the progress made by the learners or the achievements made. As such, implementing technologies and strategies to bolster the student's communication proficiency may not achieve the intended goal. In the context of this paper, the general or overall objective of the teachers should be geared towards enhancing the student's comprehension and use of language. Such goals should be in line with Kramsch [27], who advances the concept of symbolic competence and explains that learning goals should go beyond communicative competence. Zarate, Levy \& Kramsch [28] support a model of plurilingual and intercultural education, similar to Geisler et al. [29] who stress translingual and transcultural competence in linguistic learning, Thesen adhere to the model of ACTFL's Twenty-first Century Skills Map and finally, the ACTFL (1996) itself has proposed standards for teaching and learning foreign languages. Owing to this, the learning goals developed, must, therefore comprise new literacies and multiliteracies, which are an integral component of a multicultural environment.

From an analytical perspective, the world today has seen vase evolution with receipt to globalization, characterized by increased ease of information sharing and interactions and communications. As such, learners must possess the ability to adapt to the changing global trends and environments and possesses the necessary competencies to interact in a multicultural environment. As such, the learning goals must be articulated and presented in a manner that fosters the development of intercultural skills by the students. This is because "Literacy has always been a collection of cultural and communicative practices shared among the members of particular groups As society and technology changes, so does literacy" (National Council of Teachers of English Executive Committee, 2008, n.p) Owing to the fact that literacy transforms and changes with the emergence and development of new technologies, Leu et al. [30], and Barker (2010) articulates that there is the need for the learners to conceptualize and understand the emerging communication skills, social practices, and discourses that are necessary to take advantage of such technologies.

On the same note, Leu [31] explains that with due to consideration of the ever-changing technology, which in turn shapes the mediums, channels, and modes of communication, language use and communication, in general, is always new every day due to the rapid and the regular techno dynamics. Such an aspect in the communication discipline and language use leads to the rise of the 'deictic' characteristic of literacy, which Leu [31] explains that it makes it significantly had for both the learners and the teachers to adapt with the dynamism. This results in teachers and learners either being reactive or predictive to adapt to the changes in the literacy technologies.

This article hence proposes the need for the adoption of a "holistic picture" perspective, rather than the reactive or predictive techniques with respect to the deictic nature of the literacy technologies. The holistic approach can be achieved by ensuring absolute preparation of the students to handle and deal with any emergent technologies that come their way, even after school life. However, to achieves this, the teachers must define a goal or goals that encourage the students to remain attentive and keen on word meanings, material mediums, social contexts and semiotic forms that are exhibited din culturally influence relationships. Again as suggested by Lam [32] in the formulation of the learning goals, there is the need to consider learning as a process, whereby the second language learners or foreign language learners are socialized into a specific group, community or society in which the members are literate about the language and can effectively communicate. Such an approach hence gives a teacher an overview of the expected challenges by the students, the threats to getting acquitted with the new language and the opportunities that the student can capitalize on to strengthen their grasp of the language and once their proficiency in communication. This is in line with Gee [33], who perceives literacy as a construct that is intertwined with social relationships, institutions, and social-cultural contexts. The optimal goal of the teachers, must, therefore, entail remodeling the students to enhance their flexibility and make them be able to adapt to different sociocultural contexts irrespective of the technology or the medium. Analytically, in any communication, the leaders must be willing to conceptualize what to communicate, when to communicate and how to communicate it. With respect to teaching foreign language learners, Paesani, Allen, and Dupuy [34] suggest the use of literacy-based compatibility approaches to foster literacy through enhances and better ways of technological forms of language learning, use, and communication. However, such an approach calls for the teachers to ensure reconciliation between the verbal interaction in face to face and the ability of the learners to reflect, discuss, read and write critically regarding texts in distinct modalities. Thus, the outcome should be students who are able to effectively communicate in different social, cultural contests by focusing on the innovativeness and continuities across mediums and times.

\section{Pooling Necessary Resources to Achieve Set Goals}

Firstly, it would be in vain setting up technology goals if the appropriate resources are not pooled to gather to support them. As the second consideration, the teachers must as well consider the resources that are needed to develop multiliteracies in students, understanding all the social and cultural aspects of the specific society being affected by technologies. Such a question should be oriented towards combining resources in the most effect and efficient way in order to attain the learning goals developed. Focusing on the context of the second language learners or foreign language learners, assuming the predefined goals by the teacher were to ensure that the learners can eloquently, and effectively converse with the native speakers of the language, then it is upon teacher to identify the various 
opportunities in the learning process, whereby computermediated communication technologies can be implemented [35].

In such a context, the focus should not only be on textbased communication, but also on the modern word has seen vast advancement in technologies that allows sound and video transmission. In such a case, the computer-mediated communication technologies that allow the foreign language learners to virtually interact with the natives of the language either in a classroom setting or where an individual resides, via audio and video conferencing tools can be a significant step in bolstering language learning. Nevertheless, it is also critical to consider various technical challenges that could be experienced in such a learning setting. Despite the obvious fact that every participant in the learning session would require stable and fast internet connection, there are also other challenges associated with the latter, such as the lag time that is usually experienced in transmission [36]. Kern [36] further posits that people in conference calls also tend to forget to look into the camera, and more often than not, tend to focus on the interlocutor's eye, an aspect that reduces the comfort of the learners and makes the overall learning experience less spontaneous and natural.

On a different note, care must be taken when using autonomous tools that have been developed to offer automatic assistance, such as the Skype translating software, which allows individuals who are speaking in different languages to communicate with a virtual, artificial intelligence that does the translation [37]. While such advancements are a critical milestone with respect to literacy technology, such automated conversation may not go beyond the usual restraints and does not limit the awkwardness experienced in the translation of various words, which may be more contextual and not just containing the literal meaning. Therefore, pooling the necessary computer aided learning resources to entail looking more into the software, facilities, and systems that bear the capability of improving the student's a learning experience, without the possibility of evoking misconception and misunderstanding [37].

On the same token, teachers must well understand the limitations of the technologies while at the same time taking advantage of them. From a listening perspective, assuming the goal set by the teachers is to ensure the students are able to comprehend the natural speech of the natives and other fluent speakers of the language in question, various resources can be utilized, including but not limited to Vimeo and YouTube, which have a wide variety of videos and audios in spoken speech, for a wide array of languages and dialects [38]. Such resources can prove to be helpful in grooming the spoken speech of the students and improving the overall communication. Nevertheless, it is critical to note that such media are information repository containing millions of video and audio file and are literally not made for real time conversation. In scenarios where the teacher wants to engage the second language or foreign language learners in a real-time conversation environment, there is then the need to consider the computer-mediated communication technologies that support such, such as Skype and WebEx among others, which allow for real-time video and audio conferencing.

Analytically, for the learners participating in a video conference, their ability to clearly comprehend the speech of the interlocutor, they must readjust their listening skills to befit the seemingly reduced sound quality, as compared to the face to face conversation. This implies that audio and video conferencing require heightened concentration, more so for the learners who are yet to acquaint themselves with the foreign language dynamics. In online virtual world or language learning communities and forums such as Live Mocha that provides platform for learners freely interact with strangers (other learners) and instructional materials, it is pertinent for the participants to readjust their multimodal information, language, and accent in order to be able to freely interact and benefit from such a multi-lingual platform [39]. For instance, a profile picture may be deemed inappropriate in a culture and may elicit a false sense with respect the real meaning of a concept or word. Furthermore, if the main goal of learning the foreign language was to elicit the meaning of words, phrases, and sentences using the available technologies, then the teacher must also consider teaching the learners the different registers and discourse styles with respect to context and purpose.

According to Sauro [40], at first, the teacher can choose to approach the learning sessions through exposure to new learning activities and genres, such as fan fiction, wikis, and blogs; afterward, the teacher can encourage and guide the students to write their own original content and publish in a blog. In such an approach, not only would the leaders learn the dynamic of reading and writing in the foreign language, but they would also acquaint themselves with the general conventions of content writing, such as in blogs. It is also critical to first understand the native language of the speakers when fostering learning of a foreign language by the students. Such an aspect gives the teacher the ability to understand how to transfer the knowledge and contextualize the foreign language conversation, based in the native language fundamentals. For instance, if one of the learning activities entail interaction through social network communities such as Google Plus and Twitter, then it would be critical for the learners to first understand how to interact and understand discourses and norms in such platforms in their native setting.

However, Ware and Kramsch [41] note that though social network communities are associated with a wide array of benefits including but not limited to an opportunity to get familiar with social media and engagement in dialog with peers, various misconceptions and misunderstandings may arise, specifically if the learner's native language and learner's foreign language are not in line. To streamline this inconsistency and 
misunderstanding, there is the need to develop the symbolic competence whose importance was earlier on stressed with respect to the formulation of goals by teachers when engaging students in a learning session.

The symbolic competence entails being able to comprehend multiple languages and elicit the harness the semiotic diversity in a manner that enables the student to re-establish ways of observing similar events or patterns. In simple terms, this competence entails ensuring that the student can accurately transfer what he is, or she speaks in the native language to the second or native language being learned.

Mastery of this competency contributes to multilingual and intercultural competence, which in turn makes it possible for an individual to positively interact in a foreign environment without language barriers or communication hiccups. The development of the student's language or foreign language mastery, intercultural communication and pragmatic competence is a complex process that builds on a wide array of factors, including but not limited to the individual's perception of his or her culture, as well as personal attitudes, cultural understanding and awareness. In light of this, Chun's [42] study on advanced level students learning foreign language indicated that such students' exhibit effective, pragmatic strategies in their engagement with peers and general learning practices as compared to their counterparts at lower levels, who may tend to have less meaningful online engagements. While there is no specific technology that can be credited for bringing about technology development and language improvement and transformation over the years, it is apparent that technology plays have paid a significant role in the evolution.

Owing to the above argument, there is no one best technology that must be implemented to online or electronic learning of the students learning language either as a second language or a foreign language. To ensure the effectiveness of the learning process and also make sure the students reap maximum benefits from the learning sessions, it is critical for the teachers and administrators in the education sector to collaborate and employ a conglomeration of technologies, including but not limited to films, video clips, and video conferencing. Again, the creation of blogs, contribution to wikis and forums, emails, web based- and mobile base chats and online social network communities such as Facebook can be used to propagate intercultural exchange in learning foreign languages. In combination with face to face follow up discussions in class, such technologies can greatly aid in advancing the literacy technology and language comprehension, hence preventing the creation of new stereotypes and emergence of any misunderstandings.

Further, it is as well critical for the teachers or the language trainers to consider the aspect of doing with real-time information transmission and communications well as the degree of trust and confidence that the implemented technologies offer to the students. This can be used to explain the findings by Wade \& Chun
[43] who established that students engaged in a cross-cultural exchange held online tended to be extremely tactful and polite in their posting regarding their exchange partners, then in physical classes. This clearly indicates a certain level of reservation by the learners, and hence a significant gap between face to face learning environment and virtual/ online environments. Modern technologies should, therefore, be geared towards bridging this gap, and ensuring that online learning experience, more so for languages is as good as a physical learning environment.

\section{Discussion}

\section{Evaluation of How the Students Use the Learning Resources}

Essentially, in order to understand how the students are reacting to the training materials and practical sessions that entail offline and online engagements with peers and organized intercultural language events, it is critical for the teachers to carry out an evaluation in order to monitor their progress, and note any challenge that they may be facing. Essentially, evaluation remains a critical tool that is not only useful in the educational sector but also in other disciplines. In the current scenario, an evaluation on how the students are using the resources would be critical to understanding the various ways that can be used to foster the comprehension of the new language [44]. Analytically, the assessment of how students are using the provided learning resources to address the identified needs may be a process that is highly dynamic, multifaceted and challenging as well. This is because the latter may need a broader focus and critical analysis, rather than just classifying their use of the specific resources as either effective or ineffective.

In order to achieve this, the teachers must first have set milestones and deliverables in every milestone. This implies that the goals of the learning program defined must have specific outcomes that the teacher wishes to achieve in part of the learners. To ensure the effectiveness of the assessment, the teachers or evaluator must ensure that the outcomes being analyzed are based on the learner's effectiveness and efficiency in the use of the technological tool in question. In assessing this effectiveness or efficiency by the student, it is critical to first analyze the tool in terms of the language learning environment that it provides for the students, the expectations, needs, and experiences of each student and the tool/ technology's affordances in both physical class context and also in virtual online learning platforms.

\section{The learning environment}

From the perspective of the learning environment, the tools in question must be able to aid the teacher in attaining the curricular goals as well as assisting the student in achieving the set objectives. Essentially, if the learning environment provided by the technology or the resource down not positively support the delivery of content and knowledge by the teachers' then the reception of the students is as well expected to be poor 
[45]. For instance, the access and utilization of various tools discussed earlier on, such as wikis, blogs, forums, social network communities, and audio and video conferencing systems are dependent on the internet. In a scenario where the student's computer lab lacks Internet connection, then it is clear that no online learning can take place, and the teacher is not able to take advantage of the various available electronic technologies to enhance students understanding of different concepts and further their mystery of the foreign language.

In such a scenario, there would be no need to evaluate the electronic resources because of a simple reason; they are not adding any significant value to the student's performance in languages. The same case applies if the computer lab has limited number of computers, making it hard for all the students to clearly follow and partake in various online activities. In the 21st century, most of the computer aided learning technologies rely fundamentally on the internet. For instance, the Mango Languages is an online platform that offers in-class learning materials, films and lessons. However, it can only be implemented where the learners have access to the internet. Nevertheless, in the case where all the students have smartphones or tablet and can ace the internet without much hassle, an application such as the Mango app can be implemented and subsequently evaluated for effectiveness in fostering the learner's experience. The evaluation would aid in the identification of the shortcoming of the learning resources available to both the students and the teacher.

Healey et al. [46] explain that the TESOL technological standards are critical in evaluating digital learning environments. The standard provides performance indicators, standards, and goals that can be utilized by both teachers and students in the learning process. Specifically, the standard account of every standard and how the teachers and students can achieve it in both high and low technology environment is very resounding. A critical point to note, however, is that the fact that technology is complex does not make it better. Even appropriate solution to learning may emanate from simple technologies as well. It is, therefore, the responsibility of the teacher to identify the most appropriate technology from those available and implement it to achieve maximum benefits for the students, in terms of enhanced learning experience.

Afterward, it is critical for the teacher to evaluate how the student uses the specific tool considering the learning lessons offered. This can be done by administering short quantitative or qualitative surveys, asking questions or even giving assessment tests. The evaluation of how the students use the tools is mainly made to understand the areas, where they may be underperforming or having other challenges. For instance, in lessons entailing blogging, some students may face a significant challenge in understanding how to create and publish a blog, correct spelling mistakes, edit or even delete a post in the blog. While this may seemingly be technical, the latter is an integral component of literacy technology and has become a critical digital technology.

\section{The expectations and experience of students}

Essentially, every individual usually has a certain level of expectations in any activity that they engage. Likewise, in the language learning, the students have specific expectations, from both the teacher and the resources that they use. Specifically, the individuals tasked with the evaluation process must first ask themselves to whom are the resources effective? To what extent are they effective? What be done to enhance the effectiveness? The answer to these three questions can be perceived to bear the key to understanding the student expectations and experiences. To answer the questions, it is first critical to consider the various constructs that may positively or negatively affect the learner's perspectives. These include but not limited to the technological complexity, interests, educational experiences, the native language, and the proficiency level of the foreign language. In this dimension, the evaluation framework developed by Hubbard [47] can be applied.

The framework encompasses, both the learners' and the teacher's expectations and experiences, as well as the notion of affordances. Based on this model, a teacher must be able to combine his beliefs with respect to electronic devices as a delivery system with their language teaching approach and the consistency he exhibits in the two constructs; this can be defined as the teachers' fit. For instance, resources that employ the decontextualized "drill and kill" strategy may be deemed ineffective in a scenario, whereby the teacher's beliefs in regarding language learning are characterized by contextual language presentation [47]. On the same note, the leaner's fit with respect to this dimension of expectation and experience of the student also comes into play, and mainly focusses on the linguistic skills and objectives employed in the specific course and the extent to which they match the goals and outcomes of the entire learning.

\section{Digital tools affordances}

This third and final metric critically focuses on the specific constraints and affordances associated with the digital technologies and tools. In its basic definition, affordance entails the possible actions in each context that can be achieved through computer-mediated communication technologies. Such constraints and affordances are capable of positively or negatively shaping the language learning experience, by dictating what the students and teachers can or cannot do without them. Analytically, incompatibility between technology and pedagogy, as well as between the technological tools and the meaning goals, is likely to be encountered as a result of ignorance of the constraints and affordances exhibited in the computer-assisted language learning.

Smith et al. [48] examined the computer mediated communication tools affordances and came up with for 
main specificities that differentiate one computer mediated communication tool from the others; these include spatiality, modality, anonymity and temporarily. From a spatiality standpoint, during communication, the computer-mediated communication technologies exhibit differing capacities with respect to their ability to manipulate the spatial distance between the individuals communicating. For instance, Krikorian et al. [49] find the proximity of an avatar in an electronic communication has been observed to enhance the appropriateness of the participant conversations as well as social attraction in an electronic platform.

The modality aspect of the affordance dimension focuses on the availability of graphics, video, audio, and text. Availability of all these contributes to the achievement of learning goals, while unavailability limits language learners, specifically in a virtual learning environment [50]. From a different point of view, Kern [51] found that learner anxiety contributes positively to critical receptivity atmosphere, whereby individuals are more likely to exhibit critical review on a certain subject or object, if their identity is anonymous. Finally, temporary aspect focusses on the time lapse between the time the message is sent, and the time it evokes reactions from the participants in a manner that affects their behavior and discourses. In line with this, Smith [48] finds unique participatory, interactions and structural patterns in chat application programs that exhibit computer-mediated communication synchronism [52-55].

\section{Implications for Research and Practice}

The main aim of this study was to examine the use of technology in language learning, and specifically, how second and foreign language learning can be bolstered using technology through the application of computer-mediated communication technologies and tools. Analytically, it is critical to note that the trainers of language can easily be caught in discourses that are quite contradicting in decision making with respect to the technology use in a classroom context. From an analytical perspective, the teachers often view technology as an avenue of enhancing creativity and intellectual capacity. On the same, there is increasing pressure for the educators to use technology and prepare the students in order to remain technologically interconnected. The world technology today has made it easy for people to share information and ideas with their friends, families, and colleagues across the globe. Likewise, organizations are knowable to interact with a wide array of people and stakeholders across the globe. In the education sector, technology has fostered learning, by providing avenues for virtual learning, such as simulated environment and virtual classrooms for discussions and teaching [56-59].

\section{Conclusion}

This study proposes three main ways that can be employed to bolster language learning, using technology. First, any given learning process must be defined by a specific set of objectives that the learning process aims at achieving. Learning that is not guided by any specific objective is bound to fail, as there is no sure way of determining the progress made by the learners or the achievements made. In such cases, implementing technologies and strategies to bolster students' communication proficiency may not achieve the intended goal, if there are no pre-set objectives. In the context of this paper, the general or overall objective of the teachers should be geared towards enhancing the student's comprehension and use of language. Secondly, it is pointless setting up those goals if the appropriate resources are not pooled to gather to support the goals. The teachers must consider the resources that are needed to develop multiliteracies in the students, and how the socio-cultural order of the specific society has been affected by technologies. Such a question should be oriented towards combining resources in the most effect and efficient way in order to attain the learning goals developed.

Finally, every individual usually has a certain level of expectations for any learning activity in which they engage. On this point, in language learning, the students will have specific expectations, from both the teacher and the resources that they use. Most importantly the persons tasked with the evaluation process must ask themselves, for whom are these digital resources effective? To what extent are they effective? what can be done to enhance the effectiveness? Our teachers' and schools' answers to these three important questions will be the key to understanding the students' expectations, to improving and enhancing their language learning experiences in the digital era.

\section{Future Research}

Given the great number of new teaching technologies, and the wide range of new educational resources becoming available to teachers, continuing research into the most effective language learning tools and techniques is vitally necessary. This new and ongoing research should be both targeted to specific technologies and objectives, following the positivist paradigm, and interpretivist in the development of new theories and understandings of methods of language instruction, learning and acquisition. The present research has hopefully introduced some new ideas and analogies about the many ways digital technology and the internet can be used to enhance and accelerate the new multiliteracies in language arts education.

\section{References}

1. Toven-Lindsey B, Rhoads RA, Lozano JB (2015) Virtually unlimited classrooms: Pedagogical practices in massive open online courses. The internet and higher education 24: 1-12.

2. Katushemererwe F, Nerbonne J (2015) Computer-assisted language learning (CALL) in support of (re)-learning native languages: the case of Runyakitara. Computer Assisted Language Learning, 28(2): 112129.

3. Hubbard P, Levy M (2016) Theory in computer-assisted language learning research and practice. The Routledge Handbook of Language Learning and Technology p. 24-38. 


\section{Global Journal of Archaeology \& Anthropology}

4. Bauerlein M, Walesh SG (2009) The Dumbest Generation-How the Digital Age Stupefies Young Americans and Jeopardizes Our Future: New York: Jeremy P. Tarcher/Penguin, New York, USA 42: 639-643.

5. Thurlow C (2006) From statistical panic to moral panic: The meta discursive construction and popular exaggeration of new media language in the print media. Journal of Computer-Mediated Communication 11(3): 667-701.

6. Kern R (2015) Language, literacy, and technology. Cambridge University Press, UK.

7. Hubbard P (2009) Computer-assisted language learning: Critical concepts in linguistics. Routledge London, UK.

8. Chapelle CA (2017) Computer-assisted teaching and testing. In Handbook of technology, second language teaching and learning. Blackwell-Wiley, New York and London, UK.

9. Blake RJ (2013) Brave new digital classroom: Technology and foreign language learning. Georgetown University Press, Washington DC, USA

10. Kittler F (1990) The mechanized philosopher. In Looking after $\mathrm{Ni}$ etzsche, SUNY Press, New York, USA pp. 195-207.

11. Bolter JD, Grusin RA (2000) Remediation: Understanding new media MA: MIT Press, Boston, USA.

12. Manogvich L (2001) The language of new media. MIT press USA.

13. Gitelman L, Pingree GB (2003) New Media. MA: MIT Press, Boston, USA pp. 1740-1915.

14. Pecorari D (2003) Good and original: Plagiarism and patchwriting in academic second-language writing. Journal of second language writing 12(4): 317-345

15. Chandrasoma R, Thompson C, Pennycook A (2004) Beyond plagiarism: Transgressive and non-transgressive intertextuality. Journal of Language, Identity, and Education 3(3): 171-193.

16. Perkel D (2006) Copy and paste literacy? Literacy practices in the production of a My Space profile. Informal Learning and Digital Media $\mathrm{p}$ 21-23.

17. Wertsch JV (1998) Mind as Action Oxford University Press. New York, USA.

18. Walther JB (1996) Computer-mediated communication: Impersonal, interpersonal, and hyperpersonal interaction. Communication research 23(1): 3-43.

19. Ware P (2005) Missed" communication in online communication: Tensions in a German-American telecollaboration. Language Learning \& Technology 9(2): 64-89.

20. Hanna B, De Nooy J, De Nooy J (2009) Learning language and culture via public Internet discussion forums. Springer.

21. Y (1998) The effects of anonymity on computer-mediated peer review. International Journal of Educational Telecommunications 4(4): 311345 .

22. Kramsch C, Thorne S (2002) Foreign language learning as global communicative practice. Globalization and language teaching, pp. 83-100.

23. Eriksson P, Kovalainen A (2015) Qualitative Methods in Business Research: A Practical Guide to Social Research. Thousand Oaks, Sage, CA, USA.

24. McLachlan CJ, Garcia RJ (2015) Philosophy in practice? Doctoral strug gles with ontology and subjectivity in qualitative interviewing. Management Learning 46(2): 195-210.

25. Creswell J, Clark S (2007) Research Design: Qualitative, Quantitative, and Mixed Methods Approaches. ( $4^{\text {th }}$ edn), Thousand Oaks, Sage Publications, CA, USA.
26. Patton M (2002) Qualitative research and evaluation methods. Thousand Oaks, Sage Publications.

27. Kramsch CJ (2009) The multilingual subject: What foreign language learners say about their experience and why it matters. Oxford University Press UK.

28. Zarate G, Lévy D, Kramsch CJ (2008) Précis du plurilinguisme et dupluriculturalisme. Archives contemporaines

29. Geisler M, Kramsch C, McGinnis S, Patrikis P, Pratt ML, et al. (2007) Foreign Languages and Higher Education: New Structures for a Changed World: MLA Ad Hoc Committee on Foreign Languages. Profession pp. 234-245.

30. Leu DJ, Forzani E, Rhoads C, Maykel C, Kennedy C, et al. (2015) The new literacies of online research and comprehension: Rethinking the reading achievement gap. Reading Research Quarterly 50(1): 37-59.

31. Leu DJ (2000) Literacy and technology: Deictic consequences for literacy education in an information age. Handbook of reading research 3: 743-770.

32. Lam WSE (2000) L2 literacy and the design of the self: A case study of a teenager writing on the Internet. Tesol Quarterly 34(3): 457-482.

33. Gee J (2015) Social linguistics and literacies: Ideology in discourses New York: Rutledge, London, UK

34. Paesani K, Allen HW, Dupuy B (2015) A multiliteracies framework for collegiate foreign language teaching. New York: Pearson.

35. Schulze J, West SG, Krumm S (2016) The knowledge, skills, abilities, and other characteristics required for face-to-face versus computer-mediated communication: Similar or distinct constructs? Journal of Business and Psychology p. 1-18.

36. Kern R (2014) Technology as Pharmakon: The promise and perils of the internet for foreign language education. The Modern Language Journal 98(1): 340-357.

37. Rego IDMS (2015) Mobile Language Learning: How Gamification Improves the Experience. Handbook of Mobile Teaching and Learning pp. 705 .

38. Benson P (2015) Commenting to learn: Evidence of language and intercultural learning in comments on YouTube videos. Language Learning \& Technology 19(3): 88-105.

39. Lin CH, Warschauer M, Blake R (2016) Language learning through social networks: Perceptions and reality. Language Learning \& Technology $20(1): 124-147$

40. Sauro S (2014) Lessons from the fandom: Task models for technology-enhanced language learning. Technology-mediated TBLT: Researching Technology and Tasks. John Benjamins, Amsterdam, Netherlands.

41. Kramsch C (2006) From communicative competence to symbolic competence. The Modern Language Journal 90(2): 249-252.

42. Chun DM (2011) Developing intercultural communicative competence through online exchanges. CALICO Journal 28(2): 392-419.

43. Wade ER, Chun DM (2004) Collaborative cultural exchanges with CMC Teaching with technology pp. 220-247.

44. Anshari M, Alas Y, Guan LS (2016) Developing online learning resourc es: Big data, social networks, and cloud computing to support pervasive knowledge. Education and Information Technologies 21(6): 16631677.

45. Richards JC (2015) The changing face of language learning: Learning beyond the classroom. RELC Journal 46(1): 5-22.

46. Healey (2008) TESOL technology standards framework. Alexandria TESO, VA, USA. 
47. Hubbard P (2011) Evaluation of courseware and websites. Present and future promises of CALL: From theory and research to new directions in language teaching pp. 407-440.

48. Smith B (2003) Computer-mediated negotiated interaction: an expanded model. The Modern Language Journal 87(1): 38-57.

49. Krikorian (2000) Isn't That Spatial? Distance and Communication in a 2-D Virtual Environment. Journal of Computer-Mediated Communication 5: 4 .

50. Chun DM, Plass JL (1996) Effects of multimedia annotations on vocabulary acquisition. The modern language journal 80(2): 183-198.

51. Kern R (1998) Technology, social interaction, and FL literacy. New ways of learning and teaching: Focus on technology and foreign language education p. 57-92.

52. Amin R, Azim M, Kalam A (2018) The Benefit of Using Multimedia Projector in English Language Teaching Classroom. International Journal of Social Science \& Humanities 3(1): 62-76.
53. Bakhtin MM (2010) Speech genres and other late essays. Austin, TX: University of Texas Press, USA.

54. Belz JA (2003) Linguistic perspectives on the development of intercultural competence in telecollaboration.

55. Carr N (2011) The shallows: What the Internet is doing to our brains WW Norton \& Company New York, USA.

56. For language learning outside the classroom. Computers \& Education 82: 74-83.

57. Leu DJ (2010) The new literacies: Multiple perspectives on research and practice. Baker EA (Eds.), Guilford Press, USA.

58. Mackey A, Gass SM (2015) Second language research: Methodology and design.

59. National Council of Teachers of English Executive Committee (2008) The NCTE Definition of 21st Century Literacies. Urbana, IL: National Council of Teachers of English. Retrieved April 5, 2016.

\section{Your next submission with Juniper Publishers} will reach you the below assets

- Quality Editorial service

- Swift Peer Review

- Reprints availability

- E-prints Service

- Manuscript Podcast for convenient understanding

- Global attainment for your research

- Manuscript accessibility in different formats

( Pdf, E-pub, Full Text, Audio)

- Unceasing customer service

Track the below URL for one-step submission

https://juniperpublishers.com/online-submission.php 